\title{
Article
}

\section{Students, sex, and psychopathy: Borderline and psychopathy personality traits are differently related to women and men's use of sexual coercion, partner poaching, and promiscuity}

Khan, Roxanne, Brewer, Gayle, Kim, S and Centifanti, LCM

Available at http://clok.uclan.ac.uk/16493/

Khan, Roxanne ORCID: 0000-0002-3485-2450, Brewer, Gayle ORCID: 00000003-0690-4548, Kim, S and Centifanti, LCM (2017) Students, sex, and psychopathy: Borderline and psychopathy personality traits are differently related to women and men's use of sexual coercion, partner poaching, and promiscuity. Personality and Individual Differences, 107 . pp. 72-77. ISSN 0191-8869

It is advisable to refer to the publisher's version if you intend to cite from the work. http://dx.doi.org/10.1016/j.paid.2016.11.027

For more information about UCLan's research in this area go to http://www.uclan.ac.uk/researchgroups/ and search for <name of research Group>.

For information about Research generally at UCLan please go to http://www.uclan.ac.uk/research/

All outputs in CLoK are protected by Intellectual Property Rights law, including Copyright law. Copyright, IPR and Moral Rights for the works on this site are retained by the individual authors and/or other copyright owners. Terms and conditions for use of this material are defined in the policies page. 


\section{Students, sex, and psychopathy: Borderline and psychopathy personality traits are differently related to women and men's use of sexual coercion, partner poaching, and promiscuity}

Roxanne Khan, Gayle Brewer, Sonia Kim, \& Luna C. Muñoz Centifanti

Primary psychopathy traits correlate with sexual coercion, mate poaching, and lack of relationship exclusivity, reflecting instrumental use of others to fulfil personal desires. These sexual behaviors can also be explained by sexual thrill-seeking/impulsivity, or striving for relationship intimacy through fear of abandonment. Given that impulsive thrill-seeking and rejection-avoidance are related to secondary psychopathy and Borderline Personality Disorder, respectively, this study is the first to consider the independent effects of psychopathic traits versus Borderline Personality Disorder traits on sexual behaviors in a nonclinical mixed sex university student $(N=187)$ sample. Results broadly support our sexual behavior dissociation hypothesis: Unique relationships were identified between primary psychopathy traits and use of non-violent sexual coercive tactics (for women), reduced relationship exclusivity terms, and increased likelihood of mate poaching, whereas Borderline Personality Disorder traits showed an independent relationship with increased likelihood of sexual coercion (for men) and having lost a partner through poaching. These opposite experiences of mate poaching, along with the unique association between psychologically manipulative sexual coercion and primary psychopathy, are considered here in terms of their 'fit' with clinical equivalents.

\section{Key words}

Psychopathy; borderline personality disorder; sexual coercion; mate poaching; relationship exclusivity; sex-differentiation 


\subsection{Introduction}

Substantial individual variation occurs with regard to interest in sexual relationships and the behaviors men and women may employ in order to obtain sexual partners. For example, men and women may employ sexually coercive behaviors such as taking advantage of a person who is intoxicated, verbal pressure, and physical force (Koss \& Oros, 1982). Mate poaching (i.e., behaviors intended to attract a person who is already in a romantic relationship for either short or long-term relationships) is also prevalent (Schmitt \& Buss, 2001). For those in romantic relationships, sexual opportunities may be further increased by low relationship exclusivity (i.e. willingness to engage in extra-pair relationships) (Shackelford, LeBlanc, \& Drass, 2000). Previous studies have related personality to the tendency to engage in sexual coercion (Blinkhorn, Lyons, \& Almond, 2015), mate poaching experience (Kardum, Hudek-Knezevic, Schmitt, \& Grundler, 2015), and the preference for relationship exclusivity (Schmitt \& Shackelford, 2008). The current study extends these findings and considers each aspect of sexual behavior in relation to psychopathy and Borderline Personality Disorder traits.

Psychopathy is characterized by callous, self-centered, impulsive, and egotistical behavior, together with a lack of empathy (Hare 1996). Psychopathy measures typically identify two correlated though distinct factors (Harpur, Hare, \& Hakstian, 1989), yet some single factor or multiple factor instruments are available (e.g., Lilienfeld \& Widows, 2005). According to the Hare Psychopathy Checklist Revised (PCL-R, Hare, 2003), Factor 1 centers on the affective and interpersonal aspects of psychopathy and is related to manipulative, deceitful, and immoral behavior, whereas Factor 2 centers on social deviance and is associated with higher levels of impulsiveness and sensation-seeking. Hence, these are sometimes termed fearless dominance or impulsive-antisocial traits (e.g., Fulton, Marchus, \& Payne, 2010). Other measures refer to primary and secondary psychopathy (Levenson, Kiehl, 
\& Fitzpatrick, 1995), reflecting the different developmental trajectories for each psychopathy type proposed by Karpman (1941).

With respect to sexual behavior, psychopathy is associated with sexual harassment (Zeigler-Hill, Besser, Morag, \& Campbell, 2016), sexual aggression (Kosson, Kelly, \& White, 1997), sexual coercion (Harris, Rice, Hilton, \& Quinsey, 2007), and positive attitudes towards sexually predatory behavior (O’Connell \& Marcus, 2016). Although both psychopathic trait dimensions are associated with risk of committing sexual crimes, important differences occur. For example, primary psychopathy is related to manipulative, deceitful, and immoral behavior (Hare, 1996); hence, people with primary psychopathy use manipulative tactics to obtain sex without recourse to violence or threats (DeGue \& DiLillo, 2004). In contrast, secondary psychopathy involves higher levels of impulsiveness and sensation-seeking. Existing evidence for inter-relationships between sexual behavior and psychopathy has often been generated from prison samples (MacDonald \& Iacono, 2006); it is important to investigate such associations outside forensic populations.

Much of the extant research on sexual manipulation has focused on the perpetration of such acts against women; however both violence and manipulation are also used by women. Atypical sexual behaviors have been related to disorders that are often diagnosed more frequently in women than men. In particular, Borderline Personality Disorder (BPD) may be more frequent amongst women than men (Lieb, Zanarini, Schmahl, Linehan, \& Bohus, 2004), though this has been disputed (Johnson, et al. 2003). Furthermore, men and women with BPD may differ with regard to symptom expression (Hoertel, Peyre, Wall, Limosin, \& Blanco, 2014). BPD is associated with higher levels of sexual assertiveness, sexual esteem, and sexual preoccupation (Hurlbert, Apt, \& White, 1992). Furthermore, borderline traits are associated with a preference for novel rather than familiar relationships (Cheavens, Lazarus, \& Herr, 2014). Individuals with BPD, however, tend to alternate between extremes of 
idealization and vilification of partners. Intimacy for an individual with BPD, therefore, engenders an implicit threat of abandonment, which may lead to coercion in order to reduce the discomfort this fear generates. Therefore, the sexual behaviors of individuals with BPD may be motivated by sexual impulses and/or a need to achieve emotional security to counteract their disjointed interpersonal style (Agrawal et al., 2004).

Attempts to understand the trait factors behind sexual coercion use and related partner-orientated behaviours should test for unique influences of psychopathy and borderline traits, because the presence of BPD may drive a compulsive need for intimacy which produces behavior that looks like (but actually differs from) that arising from the desire to dominate a partner (Cheavens et al., 2014). Although BPD has been more strongly associated with secondary, rather than primary, psychopathy (Miller et al., 2010) these relationships vary by sex. For instance, Sprague, Javdani, Sadeh, Newman, and Verona (2012) reported that primary and secondary psychopathic traits interact in women in relation to BPD traits, but not in men. In women, primary psychopathy traits in BPD were, therefore, interpreted as behavioral sequalae of impulsivity and emotional dysregulation related to secondary psychopathy. Review of male and female BPD conditions indicates that men with this diagnosis are more likely to have psychopathy-related comorbidities, specifically antisocial and narcissistic personality disorders (Silberschmidt, Lee, Zanarini, \& Schulz, 2015). Hence, research should consider whether sex moderates the influence of psychopathy and BPD on sexual behavior.

We first explored the relationships between BPD traits and the two psychopathy personality dimensions, hypothesizing that the association would be stronger with secondary than primary psychopathic traits. With respect to sexual coercion, we hypothesized that primary psychopathy associations would remain after partialling out variance for BPD. Furthermore, as both BPD and psychopathy are associated with promiscuity (Kastner \& 
Sellbom, 2012), we examined the proclivity to 'mate-poach', anticipating that independent associations would be evidenced for each dimension examined. Since BPD is also related to an elevated frequency of neglect and abandonment reports, we also explored having had a mate poached ('mate-pinching'), hypothesizing that high BPD trait expression would elevate odds of reporting this experience. Finally, relationship exclusivity was investigated in relation to BPD and psychopathy personality dimensions, with the expectation that women would be more inclined to describe themselves using more exclusivity terms than men, although we predicted that this association would be tempered in those women with either high primary psychopathic or BPD trait expression (reflecting elevated promiscuity). Overall, on the basis that psychopathy and BPD show sex differentiation, we hypothesized that all sexual behaviors examined would show sex moderation in terms of traits relating to each of these conditions.

\subsection{Method}

\subsection{Participants}

Using opportunity sampling, 187 students were recruited in classes and public areas across a large University in the North-West of England. Respondent age ranged from 16 to 54 years $(M=22.6$ years, $S D=6.5$ years $)$ with the majority being female $(64.2 \%)$. This student sample reflected the demographic profile of the University, being mostly White European with a minority of British Asians. Three research assistants distributed questionnaire booklets to students, who were approached randomly on campus and verbally briefed on the study. To provide informed consent, if participants agreed to participate, they were asked to read a detailed briefing sheet before proceeding. Students participate in research as part of their undergraduate study expectations; thus, only one questionnaire by one student was left blank - the Mate Retention Inventory. Only one other item was left blank and the score for psychopathy was calculated on the remaining items. 


\subsection{Measures}

\subsubsection{Predictors}

Psychopathy: The Levenson Self-Report of Psychopathy Scale (LSRP; Levenson, Kiehl, \& Fitzpatrick, 1995) was developed to measure psychopathy in non-institutionalized populations. Unlike other (non-offender) psychopathy measures, the LSRP was based on the Hare Psychopathy Checklist Revised (PCL-R, Hare, 2003), a measure traditionally employed with offenders. Hence, the LSRP adopts the standard two-factor model of psychopathy: Factor 1 represents cold, affective, and interpersonal traits, whereas Factor 2 captures antisocial and impulsive traits. These are termed primary (Factor 1) and Secondary (Factor 2) psychopathy. Previous research has demonstrated correlations between the LSRP and PCL-R (e.g., Brinkley, Schmitt, Smith, \& Newman, 2001; Poythress, et al. 2010). The LSRP contains 26 items, rated on a 1 (disagree strongly) to 4 (agree strongly) Likert-scale, such that higher scores indicate higher levels of psychopathy. Example items include "I enjoy manipulating other people's feelings" (primary) and "I don't plan anything very far in advance" (secondary). The reliability and validity of the LSRP has been demonstrated in both student and offender populations (e.g., Lynam, Whiteside, \& Jones, 1999). In the present study, both primary (16 items) and secondary (10 items) subscales showed adequate internal consistency ( $\alpha=.74$ and .63 , respectively).

Borderline Personality Disorder: Personality Diagnostic Questionnaire-4 (PDQ-4, Hyler, 1994): This inventory is a self-report personality disorder questionnaire used to screen for the presence of personality disorders (e.g., Schizoid, Schizotypal, and Histrionic). The inventory is based on the Diagnostic and Statistical Manual of Mental Disorders (APA, 2000) criteria. Participants only completed the BPD section to report on the expression of Borderline Personality Disorder (BPD) traits; this BPD subscale is recognized as robust in terms of reliability and validity (Gardner \& Qualter, 2009). Previous research has used this 
measure of BPD with normative populations (e.g., Chabrol, van Leeuwen, Rodgers \& Gibbs, 2011), and to explore BPD and sexual behavior (Sansome \& Wiederman, 2009). The BPD items are nine true-false statements, such as "I either love someone or hate them, with nothing in between". Responses are scored 0 (false) or 1 (true) and higher scores indicate higher levels of BPD traits. Cronbach's $\alpha$ for our data was acceptable $(\alpha=.65)$.

\subsubsection{Outcome variables}

Sexual coercion: Postrefusal Sexual Persistence Scale (PSP Scale, StruckmanJohnson, Struckman-Johnson, \& Anderson, 2003): The PSP Scale comprises 19 sexual coercion tactic items, clustered into 4 subscales that independently measure sexual arousal (3 items), emotional manipulation and deception ( 8 items), exploitation of the intoxicated (2 items), and the use of physical force or threats (6 items). Participants were asked "Since the age of 16 , has a female/male used any of the tactics on the list below to have sexual contact with you after you have indicated 'no' to his/her sexual advances?”. Participants responded "yes" or "no" regarding options such as "Persistent kissing and touching" (sexual arousal), "Threatening to break up" (emotional manipulation and deception), "Purposely getting a target drunk" (exploitation of the intoxicated), "Using physical restraint" (physical force and threats). Responses are scored 1 (yes) or 0 (no), regarding whether they have experienced a given behavior as first perpetrator and then victim. Higher scores indicate greater experience of sexual coercion. Internal reliabilities were acceptable (except for emotional manipulation and physical force) in the present study: sexual arousal $(\alpha=.81)$; emotional manipulation and deception $(\alpha=.49)$; exploitation of the intoxicated $(\alpha=.81)$; and the use of physical force or threats $(\alpha=.40)$.

Mate poaching: Anonymous Romantic Attraction Survey (ARAS, Schmitt \& Buss, 2001) The ARAS is an 8-item measure with a 7-point response scale ranging from 1 (never) to 7 (always), designed to examine the frequency with which participants attract 
sexual partners when the target is involved in a relationship (i.e., poaching). It also provides measures of the frequency with which mate poaching is experienced by a participant or participant's partner. Higher scores indicate greater poaching experience. Example items include "Have you ever tried to attract someone who was already in a relationship with someone else for a short term sexual relationship with you?". The internal reliability could not be calculated since only single items rated on a likert scale were used as separate dependent variables.

Relationship exclusivity: A subscale of the "Sexy Seven Dimensions of Sexuality" Questionnaire (SSDSQ; Schmitt \& Buss, 2000). An SSDSQ subscale was used to determine how participants viewed themselves in terms of eight relationship exclusivity adjectives embedded within this 67 -item survey. Participants were asked to rate only the relationship exclusivity subscale items on how accurately each of the adjectives described their personality on a nine-point scale ranging from 1 (extremely inaccurate) to 9 (extremely accurate). Relationship exclusivity scores were generated from adulterous (reversed), devoted, faithful, loose (reversed), monogamous, polygamous (reversed), promiscuous (reversed), and unfaithful (reversed). Higher scores indicate higher relationship exclusivity. Internal reliability was acceptable in the present study $(\alpha=.72)$.

\subsection{Procedure}

Questionnaire booklets, containing demographic questions and the aforementioned standardized measures, were distributed by the research assistants in self-addressed envelopes. The briefing sheet informed participants of the study's aims, and encouraged them to complete the questionnaire booklet honestly and quickly. Due to the sensitive questions asked, participants were encouraged to complete the questionnaire booklet in their own time and alone, and to return this sealed in the attached envelope, either to researchers or a secure drop-in box. Respondents received no financial incentive for participating. The study was 
fully approved by the authors' institution and complies with the British Psychological Society ethical guidelines.

\subsection{Data Analysis}

BPD and primary/secondary psychopathic traits: To examine BPD traits' associations with psychopathy subtypes, and their moderation by sex, two hierarchical regressions were performed predicting psychopathy factor scores from centered BPD trait scores and sex, controlling for the alternative psychopathic dimension in each analysis and adding a multiplicative sex interaction term as a second step.

Sexual coercion: Data for each continuous predictor measure (personality disorder trait scores) were first centered by subtracting the sample mean from each participant's score. Dependent variable data were frequency counts, so Poisson regression was used. The sexual coercion data included a moderate to high proportion of zeros (ranging from .41 to .76 across subscales, except for physical force), reflecting a generally low coercion frequency. For sexual arousal strategies, $16 \%$ reported using one of the three strategies, and most participants reported using three (35\%). Eighteen percent reported using at least one emotional manipulation and deceptive strategy; $8 \%$ reported using intoxication, but a sizeable proportion used both forms (16\%). Thus, to deal with issues around low frequency variables, zero-inflated Poisson regression was selected for analysis using the Mplus 7.3 program. This statistic corrects for severely positively skewed (towards zero) data that is overdispersed (Muthén \& Muthén, 1998-2013). For the physical force subscale, the data were converted to a categorical variable to allow calculation of an odds ratio using logistic regression with $92.5 \%$ of the sample reporting no physical force whatsoever. The most common endorsements were "blocking the target's retreat" and "threatening with a weapon".

For each model, the first step regressed the dependent variables (coercion; exploitation of arousal, emotional manipulation, and exploitation of intoxication) onto the sex 
centered predictor, and sex, variables. The second step added the products generated by multiplying the predictor trait scores by a dummy variable $(0=$ male, $1=$ female $)$, with a statistically significant difference in variance accounted for between steps interpreted as evidence of sex-moderation. As scaled Log-Likelihood estimates (using Maximum Likelihood with Robust standard errors) were employed, Satorra-Bentler correction (Satorra, 2000) was consistently applied to adjust for non-normality.

Mate Poaching: Neither males nor females endorsed "almost always" or "always" on the selected items; therefore, data were collapsed from these response categories with responses for the "frequently" option. Three response outcome levels were generated (i.e. "never poached", "rarely poached" and "poached often"). Comparison of logistic regression results within Mplus 7.3 with and without collapsing response categories showed that doing so did not alter significance.

Relationship exclusivity: Hierarchical linear regression was, regressing exclusivity subscale scores onto centered predictor variables and multiplicative interactions with sex added on subsequent steps.

\subsection{Results}

Independent $\mathrm{t}$-tests suggested that BPD scores did not vary by sex, $t(185)=1.12, p=$ $.265, d=.17$, however both primary, $t(185)=5.85, p<.001, d=.89$, and secondary, $t(185)$ $=2.67, p=.008, d=.41$, male psychopathy values were significantly higher $(M=36.75, S D$ $=7.95 ; M=23.85, S D=4.77$, respectively) than females' $(M=30.33, S D=6.75 ; M=21.88$, $S D=4.86$, respectively).

Positive correlations between BPD and primary psychopathy, $r=.35, p<.001$, and between BPD and secondary psychopathy, $r=.47, p<.001$, were significant, as was overlap between primary and secondary traits, $r=.60, p<.001$, BPD was significantly more strongly correlated with secondary psychopathy than with primary psychopathy, $t(184)=2.23, p=$ 
.027 , using the Williams $t$-test (Steiger, 1980).

\subsection{Do borderline traits' relationships with psychopathy show sex-differentiation?}

BPD was nonsignificant in predicting primary psychopathy traits, unstandardized beta $=.33, \mathrm{SE}=.25, \beta=.09, t=1.31, p=.194$, but sex was significant, unstandardized beta $=-$ 4.63, $\mathrm{SE}=.91, \beta=-.29, t=-5.12, p<.001$. The sex interaction term (step 2$)$ produced a significant R-square change, $R^{2}$ change $=.02, F(1,182)$ change $=5.30, p=.022$; and indicated that males alone showed moderation of primary psychopathic traits by BPD expression, unstandardized beta $=1.02, \mathrm{SE}=.38, \beta=-.26, t=2.66, p=.009$.

For secondary psychopathy, BPD traits were significant, unstandardized beta $=.76$, $\mathrm{SE}=.15, \beta=.30, t=4.97, p<.001$, however, sex and the sex interaction were not $(\beta=.03$ and $\beta=.19$, respectively); BPD traits were similarly related to secondary psychopathy for both genders, $R^{2}$ change $=.01, F(1,182)$ change $=2.75, p=.099$.

\section{Are sexually coercive tactics uniquely related to primary psychopathy?}

Figure 1 shows the standardized betas and standard errors for the final regression model, including the interaction terms since the Satorra-Bentler test for differences in nested models using MLR was significant, $\chi^{2}(\mathrm{df}=12)=29.83, p<.01$. Gender moderated the effects of primary psychopathy and borderline personality traits on intoxication, emotional manipulation, and physical force. The positive regression coefficient indicates that women with higher primary scores were more likely to report greater use of emotional manipulation and deceptive tactics in sexual coercion. The negative coefficients for the interaction between gender and borderline in statistically predicting intoxication and physical force indicate that men with higher borderline personality disorder traits report using intoxication against their partner and threatening or in fact using physical force to sexually coerce an unwilling partner. Are mate poaching and being poached uniquely related to primary psychopathy?

Primary psychopathy traits alone were significantly and positively associated with 
both approaching attached individuals, and being approached when in a relationship (see Table 1). A 1-unit increase in this predictor score was associated with a 1.08 increase in the odds of being in a higher frequency category of poacher relative to the next frequent category (e.g. "have poached often" versus "have sometimes poached"), and a 1.06 increase in the odds of being in a higher category of being poached relative to the next lowest category (e.g. “often been poached" versus "sometimes been poached").

\section{Is experiencing mate poaching uniquely related to BPD?}

Those with higher BPD scores were significantly more likely to report that their partner had been pinched (Table 1); a 1-unit increase in this dimensional score was associated with the odds of being in a higher response category relative to the category below increasing by 1.20 (i.e. $20 \%$ uplift).

Is relationship exclusivity negatively and uniquely related to primary psychopathy or BPD traits?

Sex significantly predicted relationship exclusivity in step 1 of the linear regression (Table 2). Including psychopathy and BPD variables (step 2) resulted in a significant increase in variance, $\Delta R^{2}=.11, \Delta F(3,182)=8.43, p<.001$. This effect was due to primary psychopathy traits alone being significantly and negatively associated with relationship exclusivity. The interactions were non-significant, $\Delta R^{2}=.01, \Delta F(3,179)=.94, p=.420$.

\subsection{Discussion}

Results broadly indicate that our sexual behavior dissociation hypothesis was supported: the influences of primary psychopathic and BPD traits on sexual behaviors were dissociated. Further, the current study's results align with clinical symptoms. Primary psychopathic trait expression related to sexual coercion in a non-clinical sample fits the picture of the opportunistic 'successful psychopath', able to operate within social norms to achieve sexual satisfaction without resorting to illegal physical force or having to maintain a 
relationship. A lack of conscience in primary psychopathy facilitates taking advantage of another's sexual arousal or reduced cognitive capacity through inebriation without subsequent remorse (Harris et al., 2007). Similarly, feelings of conscience fail to inhibit mate-poaching behavior, because their seeking-out self-centered satisfaction and their preference for being in control would take precedence over any negative outcomes for others (Blackburn, 2007). Being narcissistic and charming (and hence attractive to others) have been related specifically to primary psychopathic trait expression (Falkenbach et al., 2013), and so the finding that higher expression of this subtype's traits as related to being approached whilst in a relationship and not endorsing fidelity also rings true.

Borderline traits' unique prediction of sexual behaviors was anticipated for both sexual coercion and mate-poaching behaviors, on the basis that intimacy achieved by any means would serve to calm abandonment fears (Schmahl et al., 2004). This disorder is also related to preference for novelty in relationships (Cheavens et al., 2014), sexual assertiveness, and promiscuity (Sansone \& Wiederman, 2009). Borderline traits predicted sexual coercion (intoxication and physical force) for men only. Furthermore, our study suggests BPD traits may be important in terms of relationship dissolution; they independently predicted the frequency of reporting having had a partner coaxed away, a finding that fits with research indicating that individuals with BPD interpret partner-initiated negative events as catastrophic and expect to be abandoned (e.g., Bhatia, Davila, Eubanks-Carter \& Burckell, 2013). Indeed, affective instability in BPD has dramatic consequences for relationship duration (South, Turkheimer, \& Oltmanns, 2008), thus, an individual with BPD may frame a break-up in terms of a partner being seduced away rather than by attributing it to their own doing. As this condition has been related to severe cognitive distortions (Baer, Peters, Eisenlohr-Moul, Geiger, \& Sauer, 2012) this interpretation of our data fits well with existing understanding of BPD. 
Borderline traits were more strongly associated with secondary than primary psychopathy traits, in accordance with evidence of these disorders' commonality with respect to symptoms such as impulsivity. Sprague et al. (2012) found that the two psychopathy factors derived from the PCL-R are inter-related in the context of high BPD traits in women alone, leading to the idea that Factor 1 in women (but not men) is the product of a Factor 2/BPD trait interaction.

The current study requires replication in a wider community sample. Also, the measures used in the present study were self-report which may inflate associations. Sample limitations notwithstanding, the results add to current understanding of personality disorders and sexual behaviors, because we jointly investigated psychopathy and BPD traits to capture predicted dissociations and similarities in these personality disorder traits. Future research should investigate a more diverse cross-cultural sample, control for related variables such as narcissism, and investigate clinical populations.

In summary we found that BPD and primary psychopathy trait relationships were sexdifferentiated (a BPD/primary trait association being specific to males), that primary psychopathic trait expression related to attempts to gain sex when obstructed (women only) and being open to infidelity, and that individuals high on borderline trait expression report more sexual coercion (men only) and relationship loss due to partners being seduced away (both sexes). Thus, people with primary psychopathic traits attempt to pursue sexual goals using psychologically manipulative tactics and are blasé about commitment, whereas individuals with BPD traits are sensitive to having their partners seduced away.

\subsection{References}

Agrawal, H.R., Gunderson, J., Holmes, B.M., \& Lyons-Ruth, K. (2004). Attachment studies with borderline patients: A review. Harvard Review of Psychiatry, 12, 94-104. doi: 
$10.1080 / 10673220490447218$

American Psychiatric Association. (2000). Diagnostic and Statistical Manual of Mental Disorders ( $4^{\text {th }}$ ed.). Washington, DC.

Baer, R.A., Peters, J.R., Eisenlohr-Moul, T.A., Geiger, P.J., \& Sauer, S.E. (2012). Emotionrelated cognitive processes in borderline personality disorder: A review of the empirical literature. Clinical Psychology Review, 32, 359-369. doi:10.1016/j.cpr.2012.03.002

Bhatia, V., Davila, J., Eubanks-Carter, C., \& Burckell, L.A. (2013). Appraisals of daily romantic relationship experiences in individuals with borderline personality disorder features. Journal of Family Psychology, 27, 518-524. doi:10.1037/a0032870

Blinkhorn, V., Lyons, M., \& Almond, L. (2015). The ultimate femme fatale? Narcissism predicts serious and aggressive sexually coercive behaviour in females. Personality and Individual Differences, 87, 219-223. doi: 10.1016/j.paid.2015.08.001

Brinkley, C.A., Schmitt, W.A., Smith, S.S., \& Newman, J.P. (2001). Construct validation of a self-report psychopathy scale: Does Levenson's self-report psychopathy scale measure the same construct as Hare's psychopathy checklist-revised? Personality and Individual Differences, 31, 1021-1038. doi: 10.1016/S0191-8869(00)00178-1

Chabrol, H., van Leeuwen, N., Rodgers, R.F., \& Gibbs, J.C. (2011). Relations between selfserving cognitive distortions, psychopathic traits, and antisocial behavior in a nonclinical sample of adolescents. Personality and Individual Differences, 51(8), 887892. doi: 10.1016/j.paid.2011.07.008.

Cheavens, J.S., Lazarus, S.A., \& Herr, N.R. (2014). Interpersonal partner choices by individuals with elevated features of borderline personality disorder. Journal of Personality Disorders, 28, 594-606.

DeGue, S., \& DiLillo, D. (2004). Understanding perpetrators of nonphysical sexual coercion: 
Characteristics of those who cross the line. Violence and Victims, 19, 673-688. doi: 10.1891/vivi.19.6.673.66345

Falkenbach, D.M., Howe, J.R., \& Falki, M. (2013). Using self-esteem to disaggregate psychopathy, narcissism, and aggression. Personality and Individual Differences, 54, 815-820. doi: 10.1016/j.paid.2012.12.017

Fulton, J.J., Marcus, D.K., \& Payne, K.T. (2010). Psychopathic personality traits and risky sexual behavior in college students. Personality and Individual Differences, 49, 2933. doi: $10.1016 /$ j.paid.2010.02.035

Gardner, K. \& Qualter, P (2009). Reliability and validity of three screening measures of borderline personality disorder in a nonclinical population. Personality and Individual Differences, 46, 636-641. doi: 10.1016/j.paid.2009.01.005

Hare, R.D. (1996). Psychopathy: A clinical construct whose time has come. Criminal Justice and Behavior, 23, 25-54. doi: 10.1177/0093854896023001004

Hare, R.D. (2003). Manual for the Hare Psychopathy Checklist. Revised $2^{\text {nd }}$ ed. Toronto, ON: Multi-Health Systems.

Harpur, T.J., Hare, R.D., \& Hakstian, A.R. (1989). Two-factor conceptualization of psychopathy: Construct validity and assessment implications. Psychological Assessment: A Journal of Consulting and Clinical Psychology, 1, 6-17. doi: 10.1037/1040-3590.1.1.6

Harris, G.T., Rice, M.E., Hilton, Z., Lalumiere, M.L., \& Quinsey. V.L. (2007). Coercive and precocious sexuality as a fundamental aspect of psychopathy. Journal of Personality Disorders, 21, 1-27.

Hoertel, N., Peyre, H., Wall, M.M., Limosin, F., \& Blanco, C. (2014). Examining sex differences in DSM-IV borderline personality disorder symptom expression using item response theory (IRT). Journal of Psychiatric Research, 59, 213-219. doi: 
10.1016/j.jpsychires.2014.08.019

Hurlbert, D.F., Apt, C., \& White, L.C. (1992). An empirical examination into the sexuality of women with borderline personality disorder. Journal of Sex and Marital Therapy, 18, 231-242. doi: 10.1080/00926239208403409

Hyler, S.E. (1994). PDQ-4+ Personality Questionnaire. New York.

Johnson, D.M., Shea, M.T., Yen, S., Battle, C.L., Zlotnick, C., Sanislow, C.A., ... \& Zanarini, M.C. (2003). Gender differences in borderline personality disorder: Findings from the Collaborative Longitudinal Personality Disorders Study. Comprehensive Psychiatry, 44, 284-292. doi: 10.1016/S0010-440X(03)00090-7

Kardum, I., Hudek-Knezevic, J., Schmitt, D.P., \& Grundler, P. (2015). Personality and Individual Differences, 75, 7-12. doi: 10.1016/j.paid.2014.10.048

Karpman, B. (1941). On the nee of separating psychopathy into two distinct clinical types: The symptomatic and the idiopathic. Journal of Criminology and Psychopathology, 3, $112-137$.

Kastner, R.M., \& Sellbom, M. (2012). Hypersexuality in college students: The role of psychopathy. Personality and Individual Differences, 53, 644-649. doi: 10.1016/j.paid.2012.05.005

Koss, M.P., \& Oros, C.J. (1982). Sexual Experiences Survey: A research instrument investigating sexual aggression and victimization. Journal of Consulting and Clinical Psychology, 50, 455-457. doi: 10.1037/0022-006X.50.3.455

Kosson, D.S., Kelly, J.C., \& White, J.W. (1997). Psychopathy related traits predict self reported sexual aggression among college men. Journal of Interpersonal Violence, 2, 241-254. doi: 10.1177/088626097012002006

Levenson, M.R., Kiehl, K.A., \& Fitzpatrick, C.M. (1995). Assessing psychopathic attributes in a noninstitutionalised population. Journal of Personality and Social Psychology, 
68,151-158. doi: 10.1037/0022-3514.68.1.151

Lieb, K., Zanarini, M.C., Schmahl, C., Linehan, M.M., \& Bohus, M. (2004). Borderline personality disorder. The Lancet, 364, 453-461. doi: 10.1016/S0140-6736(04)16770-6

Lilienfeld, S.O., \& Widows, M.R. (2005). Psychopathic Personality Inventory Revised (PPIR). Professional Manual. Lutz, Florida: Psychological Assessment Resources.

MacDonald, A.W., \& Iacono, W.G. (2006). Toward an integrated perspective on the etiology of psychopathy. Handbook of Psychopathy, 375-385.

Miller, J.D., Dir. A., Gentile, B., Wilson, L., Pryor, L.R., \& Campbell, W.K. (2010).

Searching for a vulnerable dark triad: Comparing factor 2 psychopathy, vulnerable narcissism, and borderline personality disorder. Journal of Personality, 78, 15291564. doi: 10.1111/j.1467-6494.2010.00660

Muthén, L.K. and Muthén, B.O. (1998-2012). Mplus User's Guide. Seventh Edition. Los Angeles, CA: Muthén \& Muthén.

O’Connell, D., \& Marcus, D.K. (2016). Psychopathic personality traits predict positive attitudes toward sexually predatory behaviors in college men and women. Personality and Individual Differences, 94, 372-376. doi: 10.1016/j.paid.2016.02.011

Poythress, N.G., Lilienfeld, S.O., Skeem, J.L., Douglas, K.S., Edens, J.F., Epstein, M., \& Patrick, C.J. (2010). Using the PCL-R to help estimate the validity of two self-report measures of psychopathy with offenders. Assessment, 17, 206-219. doi: $10.1177 / 107319110935171$

Sansone, R.A., \& Wiederman, M.W. (2009). Borderline personality symptomatology, casual sexual relationships, and promiscuity. Psychiatry, 6, 36-40.

Satorra, A. (2000). Scaled and Adjusted Restricted Tests in Multi-sample Analysis of Moment Structures. Innovations in multivariate statistical analysis (pp.233-247). Springer, US. 
Schmitt, D.P., \& Buss, D.M. (2000). Sexual dimensions of person description: Beyond or subsumed by the Big Five? Journal of Research in Personality, 34, 141-177. doi: 10.1006/jrpe.1999.2267

Schmitt, D.P., \& Buss, D.M. (2001). Human mate poaching: Tactics and temptations for infiltrating existing mateships. Journal of Personality and Social Psychology, 80, 894-917. doi: 10.1037/0022-3514.80.6.894

Schmitt, D.P., \& Shackelford, T.K. (2008). Big Five traits related to short-term mating: From personality to promiscuity across 46 nations. Evolutionary Psychology, 6, doi: $10.1177 / 147470490800600204$

Shackelford, T.K., LeBlanc, G.J., \& Drass, E. (2000). Emotional reactions to infidelity. Cognition \& Emotion, 14, 643-659. doi: 10.1080/02699930050117657

Silberschmidt, A., Lee, S., Zanarini, M., \& Schulz, S.C. (2015). Gender differences in borderline personality disorder: Results from a multinational, clinical trial sample. Journal of Personality Disorders, 29, 828-838, doi: 10.1521/pedi_2014_28_175

South, S.C., Turkheimer, E., \& Oltmanns, T.F. (2008). Personality disorder symptoms and marital functioning. Journal of Consulting and Clinical Psychology, 76, 769-780. doi: $10.1037 / \mathrm{a} 0013346$

Sprague, J., Javdani, S., Sadeh, N., Newman, J.P., \& Verona, E. (2012). Borderline personality disorder as a female phenotypic expression of psychopathy? Personality Disorders: Theory, Research and Treatment, 3, 127-139. doi: 10.1037/a0024134

Steiger, J.H. (1980). Tests for comparing elements of a correlation matrix. Psychological Bulletin, 87, 245-251. doi: 10.1037/0033-2909.87.2.245

Struckman-Johnson, C., Struckman-Johnson, D., \& Anderson, P.B. (2003). Tactics of sexual coercion: When men and women won't take no for an answer. The Journal of Sex Research, 40, 76-86. doi: 10.1080/00224490309552168 
Zeigler-Hill, V., Besser, A., Morag, J., \& Campbell, W.K. (2016). The dark triad and sexual harassment proclivity. Personality and Individual Differences, 89, 47-54. doi:

10.1016/j.paid.2015.09.048 